\title{
Entre lo propio y lo comercial. Athletic Bilbao: límites y continuidades que redefinen lo local-global
}

\author{
Between idiosyncratic features and market needs: \\ Athletic Bilbao, boundaries and continuity \\ redefining the local-global scene
}

\section{Fernando Gutiérrez-Chico*}

\footnotetext{
* Doctor en Ciencias Sociales con especialización en Antropología del Deporte por la Universidad de Salamanca. Profesor del programa internacional Sport Management en The Hague University of Applied Sciences (Países Bajos) e investigador colaborador del grupo «Deporte, cultura y sociedad» de la Universidad de La Laguna (España).

•fgutierrezchico@gmail.com http://orcid.org/0000-00025491-0347
}

\section{RECIBIDO: 17.7.2021}

\section{Resumen}

El Athletic Bilbao es conocido en el mundo del fútbol por su singular política de jugadores. Solo capta futbolistas que se hayan formado o nacido en alguna de las siete provincias que componen el País Vasco. Así, la cantera y el territorio representan las variables de pertenencia, que resultan interdependientes y recíprocamente reguladoras. Esta práctica, de carácter consuetudinario, sigue vigente en una época marcada por la globalización y la comercialización del balompié. Con todo ello, el presente artículo busca explorar los conceptos de local y global construidos por la hinchada mediante la filosofía del equipo. Se trata de conocer cómo se redefine, interpreta y persiste lo local en un contexto de globalización y mercantilización del fútbol como el actual. Para ello se emplea, principalmente, un enfoque cualitativo. Se ha optado por un trabajo de campo etnográfico. Se han realizado entrevistas semiestructuradas en profundidad a 25 seguidores del equipo, nacidos en Bizkaia y Castilla y León, que residen en esta última comunidad autónoma. Los resultados invitan a plantear el concepto de lo propio como definidor de lo local. Por el contrario, lo global se concibe como alineado con la comercialización internacional de jugadores.

Palabras clave: deporte, comercio internacional, globalización, España. 


\section{Abstract}

Athletic Bilbao is known in the world of football for its unique player policy. It only recruits footballers who were born and/or raised in one of the seven provinces that comprise the Basque Country. Thus, academy and territory represent the variables of allegiance, which are interdependent and reciprocally regulatory. This policy, of a customary nature, is still in force in an era marked by globalization and commercialization of football. In this context, the article seeks to explore the concepts of local and global built by its fans through the philosophy of the team (policy of the club). The purpose is to know how the local is redefined, interpreted, and how it persists in the current context of football globalization and marketability. To this end, a qualitative approach is mainly used. Ethnographic fieldwork has been chosen. Semi-structured interviews have been conducted in depth with 25 followers of the team, born in Bizkaia and Castilla y León, who reside in the latter autonomous community. It can be concluded that the concept of idiosyncratic features defines the local scene. Conversely, the global one is conceived as aligned with the international commercialization of players.

Keywords: sport, international trade, globalization, Spain.

\section{Introducción}

El Athletic Bilbao (equipo de fútbol ubicado en la provincia de Bizkaia, País Vasco) es conocido por su singular política de jugadores. Esta «filosofía», tal y como se conoce entre la propia institución y su hinchada, se caracteriza por el uso exclusivo de futbolistas locales. Específicamente,

se rige por el principio que determina que pueden jugar en sus filas los jugadores que se han hecho en la propia cantera y los formados en clubes de Euskal Herria, ${ }^{1}$ que engloba a las siguientes demarcaciones territoriales: Bizkaia, Gipuzkoa, Araba, Nafarroa, Lapurdi, Zuberoa y Nafarroa Behera, así como, por supuesto, los jugadores y jugadoras que hayan nacido en alguna de ellas (Athletic Club, 2018).

El topónimo Euskal Herria se refiere, en términos culturales, al país de la lengua vasca. Políticamente, como ente carece de estatus político reconocido. Se encuentra bajo la soberanía de dos Estados: España (Bizkaia, Gipuzkoa, Araba y Nafarroa) y Francia (Lapurdi, Zuberoa y Nafarroa Behera). 
Cabe subrayar que esta filosofía, vigente desde su adopción a partir de la década de $1910,{ }^{2}$ nunca se ha normalizado en sus estatutos. Por lo tanto, tiene un carácter consuetudinario, lo que conlleva un continuo proceso de redefinición y renegociación de sus límites. Tanto es así que los criterios de esta política - comúnmente conocida como «solo vascos» (Castillo, 2007a, p. 680) - se han flexibilizado o endurecido según la directiva de turno y la conveniencia del momento (Gutiérrez-Chico, 2020; MacClancy, 2007; Castillo, 2007a; Unzueta, 1999). Además, según apunta Bertelegni (2017), en teoría cualquier presidente podría fichar al jugador que quisiera sin, por ello, violar norma alguna ni tener que rendirle cuentas a ningún/a socio/a.

En cualquier caso, el territorio y la formación vía cantera se convierten, en el sentido de Barth (1976), en las fronteras que marcan la pertenencia de un/a posible jugador/a al club. ${ }^{3}$ Con todo ello, compartimos la reflexión de Shulman (2004, pp. 65-66) cuando señala que es erróneo referirse a ella como «política de no extranjeros» (tal y como se le conoce coloquialmente en ciertos círculos futbolísticos) y que, en su lugar, se debería considerar como «política de nacidos o criados vascos»o «jugadores locales». (Gutiérrez-Chico, 2020, p. 239)

Por otro lado, y a pesar de no ser un club asiduo en la compraventa de jugadores, ha protagonizado algunas de las transacciones más caras del balompié español. Esto responde a una doble tesitura. Por un lado, su dominancia en el País Vasco. Así, Shulman (2004, p. 66) lo define como «el Gulliver local, un gigante en la liliputiense región vasca», y añade que equilibra su limitación de mercado con elevadas ofertas a los jugadores destacados de los rivales vecinos. Por otro lado, la autolimitación de su filosofía acarrea una inflación en el valor de mercado de los futbolistas. La escasez de integrantes aptos

Los orígenes de esta política se remontan a la segunda década del siglo XX. En la Copa de 1911, los equipos acordaron usar jugadores extranjeros solo si estos se habían inscrito en las respectivas federaciones regionales con al menos seis meses de antigüedad. La Real Sociedad y el Barcelona, entre otros conjuntos, fueron descalificados por no cumplir la norma. En sus recursos acusaron al Athletic Bilbao de contar con dos ingleses irregulares. Consecuentemente, el equipo bilbaíno decidió retirar a estos durante un día. Los vizcaínos terminaron ganando el trofeo. A partir de entonces, se ha teorizado mucho sobre las causas que propiciaron la adopción de la filosofía. Según Bertelegni (2017), pasó de un inicio casual y práctico a ser un motivo de orgullo. Sostiene que los bilbaínos renunciaron a jugar con extranjeros para evitar problemas. Las victorias obtenidas con esta nueva política harían el resto. Toda vez que contar únicamente con jugadores locales no influía negativamente en el devenir del equipo, la filosofía había llegado para quedarse. Por otro lado, Agiriano (2010) subraya la exaltación de lo propio como origen. Remarca que a lo anterior también debe sumarse una cierta confluencia con los postulados nacionalistas de sus dirigentes. No obstante, su progresiva implantación y aceptación por la sociedad trascendería los meros postulados políticos e ideológicos hasta ser compartida generación a generación (Unzueta, 1999).

3 Debate aparte suscita la inclusión o no de la diáspora vasca y la construcción de lo vasco desde un modelo étnico o ius sanguinis (véanse Gutiérrez-Chico, 2018; Vaczi, 2011). 
para fichar anima a sus contrincantes a elevar el precio (Segurola, 2008). Así, esta práctica se conoce comúnmente como «cláusula anti-Athletic» (Gutiérrez-Chico, 2020). Uno de los casos más recientes se produjo en 2018. El defensa Iñigo Martínez se incorporó al cuadro bilbaíno procedente de la Real Sociedad tras desembolsar los 32 millones de euros de su cláusula de rescisión. Los miembros de su propia cantera tampoco se escapan a estas prácticas y, cada vez más, reciben largos contratos y altos sueldos con el fin de retenerlos (Velasco, 2018).

Con este marco en mente, el presente artículo busca explorar los conceptos de local y global construidos por la hinchada a través de la filosofía del equipo. Se persigue, así, conocer cómo se redefine, interpreta y persiste lo local, ejemplificado en el Athletic Bilbao, en un contexto de globalización y mercantilización del fútbol como el actual.

\section{Metodología}

Para abordar el presente estudio se emplea, principalmente, un enfoque cualitativo. Se ha optado por un trabajo de campo etnográfico. Se han realizado entrevistas semiestructuradas en profundidad a 25 seguidores del Athletic Bilbao, nacidos en Bizkaia y Castilla y León, y que residen en esta última comunidad autónoma. La variable lugar de nacimiento resulta especialmente importante. Recordemos que algunos de estos hinchas no podrían defender los colores del club como jugadores debido a la mencionada política de futbolistas.

Los sujetos de estudio participantes tienen una edad comprendida entre los 28 y los 61 años. ${ }^{4}$ La muestra se compone de seis mujeres y 19 hombres. ${ }^{5}$ Las entrevistas se realizaron, progresivamente y por partes, desde el 17 de mayo de 2017 hasta el 20 de febrero de 2019. Sin pretender convertirse en un estudio longitudinal, la opción de dividir las entrevistas en dos partes buscaba detectar posibles incongruencias y, por lo tanto, reducir una posible falta de precisión. Este aspecto cobra aún más sentido si tenemos en cuenta los cambiantes contextos coyunturales que se suceden en el mundo del fútbol. Cabe recordar que en el periodo cubierto se produjeron salidas de jugadores del Athletic Bilbao bastante controvertidas (Aymeric Laporte y Kepa Arrizabalaga), que se sumaban a otras igualmente sensibles (Fernando Llorente, Javi Martínez y Ander He-

4 Las edades se corresponden con las fechas en las que tuvieron lugar las entrevistas.

5 Si bien el sexo de los entrevistados no es una variable de análisis en este trabajo, se intentó conseguir paridad en la muestra. No ha sido posible por el mayor número de aficionados varones que hay en dicho territorio. No obstante, valga señalar que cuatro de las seis mujeres son dirigentes en sendas peñas del Athletic Bilbao a las que pertenecen. 
rrera). Asimismo, se reabrió el debate sobre los límites de la filosofía con la incorporación de futbolistas como Youssuf Diarra (nacido en Malí e incorporado con 17 años a la cantera rojiblanca) o Cristian Ganea (nacido en Rumanía y formado en equipos vizcaínos).

Con una duración media de 45 minutos, todas han sido grabadas y transcritas. Como herramienta metodológica para las entrevistas, se ha empleado un guion con 52 preguntas. A partir de la información registrada, se ha trabajado sobre una clasificación con los siguientes temas (ordenados en una tabla-matriz): cantera, territorio, fútbolmercantilismo, rol-Bizkaia, rol-cantera, filosofía-entrenador. La elección de Castilla y León como territorio de análisis se justifica por ser, sin contar el País Vasco, la comunidad autónoma que más peñas rojiblancas alberga. En total, 44 de las 465 que tiene repartidas por el mundo, es decir, casi un diez por ciento (Athletic Club, 2021a). Los fragmentos de las entrevistas incluidos se atribuyen a sus correspondientes participantes; no obstante, se emplean nombres ficticios para preservar su anonimato. Para distinguir a los sujetos vizcaínos y a los castellanoleoneses se han utilizado nombres en euskera para los primeros y en castellano para los segundos.

Paralelamente, se ha incurrido en un proceso de observación participante dentro de una selección de las distintas peñas oficiales que la escuadra vizcaína tiene presentes en Castilla y León. En este tiempo, se ha convivido con los diferentes seguidores y se han visto varios partidos del Athletic Bilbao en un ambiente completamente rojiblanco o mezclado con hinchas del equipo rival. También se ha intervenido en charlas y discusiones acerca del futuro del equipo y su política de jugadores.

\section{Coordenadas teóricas}

Los estudios socioculturales del deporte han incidido en la dicotomía que se ha presentado con la difusión mundial del deporte moderno, por un lado, y sus diferentes apropiaciones locales, por otro. Esto es aún más notorio en el caso del fútbol, dada su condición de disciplina dominante en buena parte del planeta. Como remarcan Robertson y Giulianotti (2006, p. 10), «no tiene un verdadero rival que pueda poner en duda su condición de juego mundial». La transcendencia sociocultural del balompié se ha movido desde su capacidad como arena representativa de su entorno inmediato hasta el desarrollo de códigos de interpretación propios, pasando por su habilidad transformativa.

Villena Fiengo (2003a, p. 26) nos invita a reflexionar acerca de la función de este deporte como foro público «donde se elaboran y refuerzan identidades tanto prefutboleras como específicamente futboleras». Consecuentemente, una primera reapropiación 
local de este fenómeno global sería su aplicación como reflejo de la sociedad. Así, Pulleiro (2015) apunta que este deporte ni surgió ni se encuentra en una burbuja independiente; su evolución está atravesada por su entorno inmediato (político, legislativo, social, económico...). Para el caso español, Spaaij y Viñas (2013) afirman que los estadios se transformaron, paulatinamente, en espacios donde diversos colectivos volcaron sus existentes pulsos simbólicos antes, incluso, que las tensiones propiamente futboleras. De este modo, su relevancia comunitaria permite expresar y reformular un gran abanico de constructos sociales: locales, étnicos, religiosos, de género... (Bradley, 2006).

Sin embargo, la dimensión que ha adquirido el balompié en las últimas décadas nos conduce a pensar que su trascendencia va mucho más allá de una mera función de espejo. Su repercusión actual no se limita únicamente a la recopilación de eventos circundantes. Siguiendo a Feixa (2003), produce identidades culturales propias y nuevas, con una dialéctica concreta. Su expresión es multiforme, ya sea individual (identificarse con un club como una manera moderna de construcción social), colectiva (nuevos sentimientos de pertenencia), institucional (lógicas empresariales) o transnacional (bases locales que se abren a nuevas escalas con su correspondiente red de significados).

En la otra cara de la moneda está el intenso proceso de globalización en el que se encuentra el fútbol actualmente, con un marcado prisma mercantilista. Esta apreciación resulta relevante para el contexto de esta investigación, ya que el cariz intrínsecamente comercial del balompié moderno difiere de la globalización tardodecimonónica de este deporte como difusión cultural. Giulianotti (1999, p. 24), precisamente, señala que ello ha hecho que «las viejas fronteras entre lo local, lo regional, lo nacional y lo global [sean] rutinariamente penetradas o colapsadas». Asimismo, Giulianotti y Robertson (2007, p. 174) defienden que hasta «el más localista de todos los clubes está repleto de influencias cosmopolitas en términos de jugadores, entrenadores, sistemas tácticos, métodos de marketing o formas de animar que se originaron previamente en otras localidades culturales».

En este contexto, surgen dos debates significativos. Por un lado, siguiendo a Villena Fiengo (2003b), los procesos globalizadores traen una renegociación y una reformulación entre identidad y territorio. Por lo tanto, cabe cuestionarse cómo afecta esta modificación la relación entre el fútbol y la comunidad local. Por otro lado, según Alabarces (2002, p. 10), debemos analizar cómo permanece lo local dentro de la universalización cultural presente vía fútbol, «que se globaliza [...] y al mismo tiempo radicaliza su tribalismo, o su localismo, o su nacionalismo». 
Como suma de lo anterior, resulta pertinente rescatar la adaptación que Giulianotti (1999, p. 24) hace de los términos flujo y scape, acuñados por Appadurai. ${ }^{6}$ Define el estado actual del fútbol como «soccerscape», apelando a la «circulación geocultural de las partes constitutivas del fútbol: jugadores y entrenadores, aficionados y oficiales, bienes y servicios, o información y artefactos». Dentro de esta perspectiva de la globalización futbolera, y en el marco de esta investigación, nos centramos en esa circulación mundial de jugadores. Para ello, queremos poner el foco en la llamada Ley Bosman y sus consecuencias legalmercantiles.

La resolución del caso Bosman, en diciembre de 1995, supuso la extensión del derecho a la libertad de movimiento a los deportistas. Todo con base en su consideración como trabajadores por el Tribunal de Justicia de la Unión Europea. Igualmente, la Corte decretó que la regla 3+2 de la UEFA sobre los jugadores extranjeros era ilegal ${ }^{7}$ (Gil Araújo, 2002). Este ha sido el caso que más trascendencia ha tenido en la estructura del fútbol. La jurisprudencia que sentó permitió futuras acusaciones que, a la larga, han ampliado los límites territoriales de incorporación de futbolistas. ${ }^{8}$

La aplicación al deporte de estos principios de libre movilidad ha marcado un antes y un después. Tal interpretación jurídica ha planteado un debate sobre los fundamentos del fútbol. A la hora de respaldar su decisión, el Tribunal de Justicia de la Unión Europea justificó su medida en una concepción del deporte como actividad económica. Curiosamente, en aquellos primeros instantes, varias federaciones (entre ellas la española) protestaron al contemplar que el fútbol no era un asunto comercial. Así, de acuerdo con Gil Araújo (2002, p. 68), se abre paso una doble interpretación del balompié. Su perspectiva como actividad económica permite el derecho de libre circulación de los jugadores comunitarios, en cuanto trabajadores, y anula los cupos por nacionalidad aplicados previamente. Su visión como actividad cultural, por el contrario, supone la defensa del espacio deportivo como esfera de expresión identitaria local, restringiendo la presencia de futbolistas considerados foráneos.

Las consecuencias de esta regulación se han plasmado en varios frentes. Uno de sus impactos iniciales fue el derrumbe del proteccionismo del mercado futbolístico por ley-y, por ende, una cierta especulación del papel de las canteras. De hecho, Schaffhauser (2009) mantiene que los clubes comenzaron a buscar jóvenes virtuosos allende

Según Appadurai, el término flujo se refiere a la circulación global de servicios, personas y productos culturales. Consecuentemente, este flujo opera mediante una serie de scapes, tales como financescape o mediascape (tomado de Giulianotti, 1999).

7 Según esta normativa, la UEFA requería a las distintas federaciones nacionales que limitaran el número de jugadores foráneos durante un partido de primera división. Solo se podían alinear tres extranjeros más dos asimilados.

8 Para profundizar en la sentencia Bosman o consultar más casos, véanse Marcén, 2016; Gardiner y Welch, 2011; Gil Araújo, 2002. 
sus academias-territorios a fin de beneficiarse de unos costes más bajos y unas normas más laxas lejos de Europa. Además, Giulianotti (1999) señala otras tres grandes secuelas. De un lado, ha aumentado la movilidad de futbolistas, hasta el punto de que la mayoría de los equipos del continente tiene varios líderes extranjeros. De otro lado, se ha desequilibrado el poder entre los clubes del viejo continente. Como resultado, ha aumentado la brecha a favor de los económicamente más fuertes, dada su facilidad para fichar a los mejores futbolistas. Además, también se ha disparado la desigualdad de salarios entre los jugadores.

Complementariamente, Castillo (2007b) reflexiona sobre la erosión que esta circulación ha causado en la fidelidad a un club. A su juicio, esta fidelidad se ha resquebrajado por una doble vía: la pérdida de importancia del futbolista local y la percepción del jugador como activo financiero. A ello se suma, de acuerdo con Segurola (2008), el empoderamiento de los grandes clubes, lo que les permite acechar a cualquier joven que despunte (por no mencionar el rol de los representantes, cuya intermediación persigue un beneficio económico). Precisamente, en este sentido, el Athletic Bilbao ha vivido, en los últimos años, la salida de algunos de sus canteranos más destacados, como el portero Kepa Arrizabalaga (al Chelsea en 2018), Aymeric Laporte (al Manchester City en 2018) o Fernando Llorente (a la Juventus en 2013).

\section{Redefiniendo lo locall-global}

A continuación, el presente artículo explorará los conceptos de local y global construidos por la hinchada a partir de la política de jugadores del Athletic Bilbao. Así, se busca conocer cómo se redefine, interpreta y permanece lo local, ejemplificado mediante dicha filosofía, en un contexto de comercialización y globalización del fútbol como el vigente. Para ello, un importante punto de partida es centrarse en sus límites: cantera y territorio. Cabe preguntarse hacia dónde orientar la estrategia de captación de futbolistas.

Algunos académicos argumentan que la atención invertida en la cantera es la causa que explica la identificación de tanta gente con el club. MacClancy $(2003,2007)$ subraya que esta apuesta por el talento joven provoca un cierto vínculo de fraternidad entre los jugadores y la afición. Siguiendo al investigador británico, los hinchas son testigos del esfuerzo de sus vecinos a la par que se dan cuenta de que las generaciones venideras pueden alcanzar el primer equipo si se esfuerzan y sirven. Igualmente, Quiroga Fernández (2019) observa en este apoyo popular a los más jóvenes una forma de resistencia ante los fichajes millonarios de otras escuadras. Sumado a esto, Bertelegni 
(2017) remarca que la incorporación de otros futbolistas vascos nunca puede suponer el desplazamiento de un canterano formado en Lezama. ${ }^{9}$

Según observamos en nuestro trabajo de campo, entre los seguidores que dan un mayor peso a la escuela formativa destaca el aprecio a lo propio y a unos valores. Se refieren al producto formado dentro del Athletic Bilbao. Opinan que esa es la verdadera muestra del espíritu del club. Así lo indica Irene, quien suscribe que el compromiso toma forma a través del patrocinio de la cantera: «La idea de que me gusta un club con valores y ligado a la tierra y a las tradiciones que representan concuerda más con que tenga un espíritu de cantera». Igualmente, Gorka apunta al «One Club Man; esa fidelidad a un equipo es lo que nos hace diferentes. Cuando perdamos eso seremos un club de un pueblo grande, estaremos en el limbo y seremos un club más».

Otros reivindican esa resistencia frente al mercantilismo del deporte señalada antes. Según comenta Jesús, «Es más importante tener unas convicciones y mantenerlas, aunque pierdas, que traicionarte para ganar. Lo de los extranjeros no es porque sean extranjeros, sino por la dinámica comercial». También hay quien alude a su falta de nacionalismo vasco. Josu, por ejemplo, subraya: «Como no tengo sentimiento nacionalista, el hecho de que sea vasco me da igual, pero lo que me importa es que se mantenga la filosofía de ser un club de cantera».

Contrariamente, otros autores han resaltado la territorialidad como factor clave para describir la particularidad localista del Athletic Bilbao. Segurola (2008) se centra en una relativa dominancia del club en el País Vasco y articula que, por momentos, se ha apuntado al mal hacer de Lezama como justificación de una serie de intereses translúcidos que han empujado a la entidad a fichar en escuelas cercanas. Por su parte, la propia institución se manifiesta de forma más contundente. En el número 61 de su revista oficial publica un reportaje sobre el modelo del club. Su tesis principal es que, pese a apoyar a su academia, la verdadera fortaleza y originalidad es sostener el principio de territorialidad:

La mayor y crucial diferencia entre el Athletic y el resto de clubes de cantera no está en el mayor o menor número de canteranos con los que compiten. [...] La verdadera originalidad del Athletic Club y quizá su mayor mérito radica en mantener el principio de territorialidad como filosofía deportiva más allá de la cantera. [...] El reto no es solo sacar de la propia cantera jugadores de primer nivel para el equipo; el verdadero desafío consiste en incorporar futbolistas nacidos o formados en Euskal Herria lo suficientemente competitivos para cubrir aquellas posiciones más débiles. [...] Porque nos olvidaríamos de aquellos otros futbolistas na- 
cidos o formados que, no siendo tan mediáticos ni reconocidos, sí han sido lo suficientemente competitivos como para rendir a buen nivel en sus demarcaciones. (Athletic Club, 2019, pp. 34-35)

Entre los seguidores entrevistados, los partidarios de fortalecer el ámbito territorial destacan dos razones principales. Por un lado, el riesgo de ser débiles si las futuras generaciones no están lo suficientemente preparadas. Manuel indica que «con la filosofía actual podría darse el caso de que no hubiera ningún canterano, por difícil que sea» y defiende la contratación de los mejores futbolistas vascos, por muy costoso que resulte. Por otro lado, aboga por que la representatividad del club se base en gente local $\mathrm{y}$, consecuentemente, apostar por lo propio. Joseba lo sintetiza en que «aunque no de la cantera, serían de la tierra».

Otro aspecto territorial que también requiere un análisis es la mayor o menor representatividad vizcaína en la plantilla. Una hipotética ausencia de jugadores de esta provincia (donde radica el club) genera un mayoritario rechazo entre los entrevistados. Varios interpretan el binomio Athletic = Bilbao/Bizkaia como indisociable; por ello, la falta de futbolistas de este territorio histórico generaría un cierto efecto «deslocalizador». Como señala Jesús, «aunque estuviese compuesto por jugadores del País Vasco, yo creo que la base siempre ha sido gente de Bilbao y alrededores». Esta idea también la suscribe Josu al decantarse por integrantes vizcaínos: «Me siento más identificado con Bilbao, Bizkaia. Al fin y al cabo, es gente que he podido tener ahí cerca».

En esta línea, algunos hinchas apelan a una «pérdida de la esencia». Es el caso de Nekane, para quien «habría que darles más visibilidad, porque su sentimiento de pertenencia no es el mismo» que el de un futbolista de otra provincia vasca. Y agrega que «un vizcaíno va a tirar más que un donostiarra», aunque reconoce el compromiso total de guipuzcoanos como Aduriz. Otros lo suplementan con cuestiones vinculadas, tales como la diáspora. Para aficionadas como Irene, la incorporación de los descendientes de vascos solo sería admisible si fueran hijos de vizcaínos. A su modo de ver, «es una manera de limitarlo, que no nos venga un descendiente de un giputxi ${ }^{10}$ [sic], sino de uno de Bizkaia».

Contrariamente se sitúan los que anteponen la formación en la academia del club frente al origen del deportista. Así, Andoni recuerda que la ausencia de vizcaínos «ya ha ocurrido, pero es que son jugadores que han pasado por Lezama, saben lo que es, cómo es y han jugado allí». Gorka suscribe esta postura a la par que ensalza la fidelidad al club

El término giputxi alude a la gente de la provincia de Gipuzkoa. Se usa frecuentemente entre la población vizcaína o, como se observa, entre seguidores del Athletic Bilbao. Según las circunstancias, puede adoptar un tono despectivo. Asimismo, puede servir para establecer esa frontera entre el nosotros vizcaíno y el ellos guipuzcoano. 
frente a la territorialidad. Para él «los límites administrativos encorsetan mucho la mentalidad de la gente», y asevera que «esos límites están muy por debajo de lo que tiene que ser nuestra filosofía y la capacidad de representación simbólica que tiene, más que sobre un espacio, sobre unos valores». Precisamente, esa lealtad a los colores y la interiorización de un modelo de equipo singular es lo que resalta Aritz. A su juicio, esa debe ser la preferencia por delante de la procedencia del jugador. Consiguientemente, piensa que

[...] lo que hay que priorizar es a la gente a la que se le ha inculcado el espíritu del Athletic. Sea de donde sea. Es más, juegan riojanos, navarros, vascofranceses... Entienden lo que es el espíritu del Athletic y eso se circunscribe a Euskal Herria.

Como se ha adelantado, la comercialización del balompié también ha llegado a las academias de los distintos equipos. Para las estructuras de ciertas instituciones, la formación de futbolistas talentosos se analiza, a partes iguales, en términos deportivos y económicos. La venta de jugadores se observa como una forma de cuadrar las cuentas o, en ocasiones, generar beneficios e incorporar a nuevos integrantes. Por lo tanto, el aspecto financiero toma un papel principal. En consecuencia, preguntamos a nuestros entrevistados sobre el propósito de la cantera del Athletic Bilbao: ¿formar jugadores para que representen al equipo o formarlos para venderlos y poder traer a los mejores futbolistas vascos?

La respuesta es unánime a favor de la primera opción. Reflexionan que el objetivo de Lezama debe ser preparar, en todos los ámbitos, a los próximos miembros de la primera plantilla. Lo contrario significaría encaminarse hacia la mercantilización que tanto evitan. Al respecto, Gorka acentúa: «Si no, seríamos Mareo o Tajonar, y yo todavía espero que seamos algo diferente. Quiero creer que Lezama es más La Masía que Mareo». Se refiere así al reciente éxito de la cantera del F. C. Barcelona y su producción de jugadores de clase mundial (Messi, Xavi, Puyol, Iniesta, Piqué...) que, de hecho, han liderado al conjunto culé. Opuestamente, alude a las academias del Sporting Gijón (Mareo) y del C. A. Osasuna (Tajonar) como continuas exportadoras de futbolistas a cambio de nuevos ingresos. Otros hinchas, como Pedro, también secundan una visión de Lezama como escuela de los jugadores del mañana. No obstante, alberga cierto miedo sobre la realidad financiera que se ha apoderado del balompié actual y sus efectos sobre la cantera bilbaína: «El mercado, evidentemente, en el momento en el que a nosotros nos sale un jugador un poco bueno, los de siempre están ahí con el cazo [sic] y adiós, muy buenas. Ante eso, ¿quién se resiste?».

Complementariamente, en esta contrastación entre lo local y lo global, miramos hacia la figura del entrenador. Los técnicos han quedado excluidos de los límites establecidos por la filosofía del club. En sus más de 120 años de historia, el Athletic Bilbao 
ha tenido numerosos directores técnicos extranjeros e incluso de otras partes de España. Concretamente, la lista está encabezada por preparadores británicos (9), seguidos de españoles no vascos (3), argentinos y serbios (2), así como de húngaros, alemanes, checos, brasileños, franceses y austríacos (1) (Athletic Club, 2021b).

Entre los participantes de la investigación se observa unanimidad ante la contratación de un mánager extranjero si se diera el caso. Es un asunto que no les inquieta y que, a su juicio, no contradice la política de captación del club. De hecho, hinchas como Endika remarcan que «el Athletic se ha nutrido de entrenadores de todo el mundo desde sus inicios». De forma similar se manifiesta Gorka, quien admite:

Nosotros, en esto de los entrenadores, somos los primeros que trajimos a los ingleses. Mr. Pentland, Ronnie [Allen]... Y el último Bielsa, que volvió a traernos fútbol a San Mamés después de no sé cuántos años. [...] Bielsa nos devolvió la emoción de ir a dos finales.

Reconoce, por tanto, la buena labor que han tenido los técnicos extranjeros en el desempeño del club, con alusión incluida a sendas finales de Europa League y Copa disputadas en 2012 a las órdenes del albiceleste Marcelo Bielsa. Esta interpretación de que con preparadores de fuera el equipo rinde mejor es sumamente compartida. En su caso, Leire no titubea a la hora de afirmar que «los extranjeros siempre nos han ido bien en el banquillo, o casi siempre». Por su parte, Nekane no descuida el apartado táctico ni la gestión del grupo, aunque suscribe que los entrenadores de fuera han beneficiado al club: «Más que de aquí o de allí, quiero ver cómo maneja al grupo. Si nos ceñimos a los últimos años, nos ha ido mejor con un entrenador de fuera».

\section{Conclusiones}

Una primera reflexión general es admitir la masculinidad existente en las narrativas presentadas en este texto. Partiendo de una búsqueda (infructuosa) de paridad en la muestra, los comentarios analizados apenas se sirven de ejemplos femeninos. Esta es una variable sumamente relevante a la hora de proceder a un estudio holístico de este enfoque.

Una vez subrayado lo anterior, en términos generales apuntamos que, en este caso de estudio, el concepto de local se redefine sobre dos factores principales: la cantera y el territorio. Por un lado, la cantera simboliza una serie de valores atribuidos al club. Por otro, el territorio consolida ese rol representativo de los equipos en función de su origen, que se ha erosionado con la mercantilización del fútbol. Ambas variables forjan una especie de sinergia que da lugar a un tercer criterio: lo propio. Consecuentemente, 
este sentido de propiedad, bien por formación (cantera), bien por origen común (territorio), apela tal relación de pertenencia comunitaria y proximidad.

Descartamos que una de las dos variables tenga mayor peso que la otra. El razonamiento es el siguiente. Si se interpreta esta política de jugadores solo en clave territorial, se fomentará la cantera, pero igualmente se podrán adquirir otros futbolistas vascos pagando altas sumas de dinero. Por consiguiente, el club se tornará un actor más del fútbol comercializado. Contrariamente, si la atención se pone en la cantera, se pueden incorporar jóvenes de todas las zonas del planeta para entrenarlos a costa de suculentos desembolsos. Por ello, sostenemos que ambos factores constituyen los límites de esta construcción de lo local a partes iguales y, especialmente, de forma complementaria. En otras palabras, ambos se autorregulan y equilibran entre sí. Están interrelacionados y no se puede comprender el uno sin la otra. Asimismo, entendemos el concepto de lo global como la comercialización del balompié en su más amplio sentido (jugadores, seguidores, financiación...).

Ello nos conduce a subrayar un detalle más. Esta interacción demuestra que $1 o$ local necesita de lo global para su reafirmación. Confirma que la construcción del yo/nosotros se hace en función de una intersubjetividad con un otro/ellos y no por razones esencialistas. El Athletic Bilbao y su hinchada no pueden reivindicar la cantera y la territorialidad - lo local - como constructos identitarios por la mera existencia de su filosofía. Al contrario, esta política de jugadores adopta tal significación porque los otros equipos han abrazado lo global, en forma de desterritorialización, movidos por cargas comerciales. Eso sí, planteamos una cuestión para sucesivos estudios relacionados. ¿Es esta filosofía un fin en sí misma o, por el contrario, se ha transformado en el medio? Lo segundo invitaría a emplear todas las teorías mercantilistas sobre el club en tanto en cuanto se convertiría en producto mercadotécnico.

Por otro lado, rebatimos las interpretaciones xenófobas de Crolley y Hand (2002). Como se observa, dicha política de jugadores responde más a una cuestión de propiedad y no tanto de origen. Compartimos así con Shulman (2004) que ninguna institución xenófoba estaría tan orgullosa de sus orígenes extranjeros como el Athletic Bilbao y su anglofilia.

Finalmente, nos atrevemos con una breve deliberación de por qué tal filosofía no es aplicable a los entrenadores. A nuestro juicio, la razón se halla en su propia raíz. Puesto que se originó a causa de un problema con la alineación de ciertos jugadores británicos, cobra sentido que los técnicos permanecieran fuera de esta aplicación. Sin embargo, parece relevante indicar que, en aquella época (finales de la década de 1910), el papel de los místeres era secundario y no tenía el peso actual. Por lo tanto, avistamos un nuevo espacio en el que construir lo local, toda vez que el mercadeo de entrenadores ya es una realidad. 


\section{Bibliografía}

Agiriano, J. (2010). Una cuestión de orgullo: Las 24 Copas del Athletic Club (1902-1984). Bilbao: BBK.

Alabarces, P. (2002). Fútbol y patria: El fútbol y las narrativas de la nación en la Argentina. Buenos Aires: Prometeo Libros.

Athletic Club. (2018). Un club único: Todos los futbolistas del Athletic Club han nacido o se han formado en Euskal Herria. Recuperado de https://www.athleticclub.eus/filosofia/cual-es.

Athletic Club. (2019). Un mundo para el Athletic. Revista Oficial, 61, 32-37.

Athletic Club. (2021a). Peñas: Athletictzales unidos en todos los territorios. Recuperado de https://www.athletic-club.eus/club/penas-oficiales/.

Athletic Club. (2021b). Entrenadores. Recuperado de https://www.athletic-club.eus/ entrenadores.

Barth, F. (1976). Los grupos étnicos y sus fronteras. México: Fondo de Cultura Económica. Bertelegni, S. (2017). Athletic Club di Bilbao: L'utopia continua. Turín: Bradipolibri.

Bradley, J. M. (2006). Sport and the contestation of ethnic identity: Football and irishness in Scotland. Journal of Ethnic and Migration Studies, 32(7), 1189-1208.

Castillo, J. C. (2007a). Play fresh, play local: The case of Athletic de Bilbao. Sport in Society, 10(4), 680-697.

Castillo, J. C. (2007b). The concept of loyalty and the challenge of internationalisation in post-modern Spanish Football. International Journal of Iberian Studies, 20(1), 2340.

Crolley, L., y Hand, D. (2002). Football, Europe and the press. Londres: Frank Cass.

Feixa, C. (2003). Un antropólogo en el fútbol. En F.X. Medina y R. Sánchez (eds.), Culturas en juego: Ensayos de antropología del deporte en España (pp. 73-102). Barcelona: Icaria.

Gardiner, S., y Welch, R. (2011). Bosman - there and back again: The legitimacy of playing quotas under European Union sports policy. European Law Journal, 17(6), 828849.

Gil Araújo, S. (2002). Fútbol y migraciones: La sentencia Bosman en el proceso de construcción de la Europa comunitaria (Crónicas desde España). Migraciones Internacionales, $1(3), 55-78$.

Giulianotti, R. (1999). Football: A sociology of the global game. Cambridge: Polity Press.

Giulianotti, R., y Robertson, R. (2007). Recovering the social: Globalization, football and transnationalism. Global Networks, 7(2), 144-186.

Gutiérrez-Chico, F. (2018). Entre Asensios y Diarras: El Athletic Bilbao y la construcción de identidades. Revista Latina de Sociología, 8(3), 160-171. 
Gutiérrez-Chico, F. (2020). Vencer menos para ganar más. Singularidad deportiva, vínculo territorial y transversalidad de la identidad a través de hinchas del Athletic Bilbao. (Tesis doctoral). Universidad de Salamanca, Salamanca.

MacClancy, J. (2003). Nacionalismo en juego: Los vascos de Vizcaya y el Athletic Club de Bilbao. En F. X. Medina y R. Sánchez (eds.), Culturas en juego: Ensayos de antropología del deporte en España (pp. 137-158). Barcelona: Icaria.

MacClancy, J. (2007). Expressing identities in the Basque arena. Oxford: James Currey.

Marcén, M. (2016). The Bosman ruling and the presence of native football players in their home league: The Spanish case. European Journal of Law and Economics, 42(2), 209-235.

Pulleiro, C. (2015). Fútbol y política: Reflexiones de una relación compleja a través del festival de cine Thinking Football. Materiales para la Historia del Deporte, 13, 37 46.

Quiroga Fernández, A. (2019). Así también se hace patria: Fútbol y franquismo en Cataluña y el País Vasco (1939-1977). Hispania Nova, 17, 269-302.

Robertson, R., y Giulianotti, R. (2006). Fútbol, globalización y glocalización. Revista Internacional de Sociología (RIS), 64(45), 9-35.

Schaffhauser, P. (2009). El fútbol profesional como guion: Apuntes para estudiar la relación migración-identidad. Razón y Palabra, 14(69), 1-11.

Segurola, S. (2008). La ley Bosman y el Athletic. En L. V. Solar y G. Reguera (eds.), Cultura(s) del fútbol (pp. 185-189). Vitoria-Gasteiz: Bassarai.

Shulman, J. (2004). The last genuine local team: Athletic Bilbao surviving in the spanish league.Dialogues@RU, 3, 57-71.

Spaaij, R., y Viñas, C. (2013). Political ideology and activism in football fan culture in Spain: A view from the far left. Soccer \& Society, 14(2), 183-200.

Unzueta, P. (1999). Fútbol y nacionalismo vasco. En S. Segurola (ed.), Fútbol y pasiones políticas (pp. 147-168). Madrid: Debate.

Vaczi, M. (2011). Subversive pleasures, losing games: Basque soccer madness. South African Review of Sociology, 42(1), 21-36.

Velasco, J. (2018, 7 de junio). El Athletic, uno más en la jungla. Marca. Recuperado de https://www.marca.com/futbol/athletic/2018/06/07/5b19593fe5fdea62628b45f4.html.

Villena Fiengo, S. (2003a). El fútbol y las identidades: Prólogo a los estudios latinoamericanos. En P. Alabarces (ed.), Futbologías: Fútbol, identidad y violencia en América Latina (pp. 21-35). Buenos Aires: Consejo Latinoamericano de Ciencias Sociales.

Villena Fiengo, S. (2003b). Gol-balización, identidades nacionales y fútbol. En P. Alabarces (ed.), Futbologías: Fútbol, identidad y violencia en América Latina (pp. 257271). Buenos Aires: Consejo Latinoamericano de Ciencias Sociales. 